\title{
ORIGINAL ARTICLE \\ The associations between diet and physical activity with body composition and walking a timed distance in adults with Prader-Willi syndrome
}

\author{
Susan G. Woods'*, Allen Knehans', Sandra Arnold², Carol Dionne², Leah Hoffman', \\ Peggy Turner', and Jonathan Baldwin ${ }^{3}$ \\ 'Department of Nutritional Sciences, University of Oklahoma Health Sciences Center, Oklahoma City, OK, USA; \\ 2Department of Rehabilitation Sciences, University of Oklahoma Health Sciences Center, Oklahoma City, OK, USA; \\ ${ }^{3}$ Department of Medical Imaging and Radiation Sciences, University of Oklahoma Health Sciences Center, \\ Oklahoma City, OK, USA
}

\section{Abstract}

Background: Research on aging in Prader-Willi syndrome (PWS) is limited, although people with PWS are living longer. Individuals with PWS present with high fat mass, low lean mass, and low levels of physical activity (PA). Previous reports in children and young adults with PWS show inadequate nutrient intake and body fat percentage indicating obesity. Previous studies in PWS rarely included individuals beyond young adulthood, especially studies conducted in the United States. This study includes adults from 18 to 62 years of age, and includes 19 of the estimated 60 adult individuals with PWS in Oklahoma. Because individuals with PWS are living longer, information must be provided on aging with PWS. This study is a report of the initial data for a planned longitudinal study on aging with PWS.

Objective: Determine associations between body composition, diet, PA, and a timed walk for adults with PWS, and to assess adequacy of dietary intake for those individuals aging with PWS.

Design: This cross-sectional investigation determined dietary habits, PA, and body composition of adults with PWS, and tested associations between these variables.

Results: Participants ranged in age from 18 to 62 years. They had healthier body composition, at $26.8 \%$ body fat, than previously reported. Mean body mass index (BMI) was in the overweight range at 26.7. Those who consumed higher amounts of fat (as a percent of total kilocalories) had statistically significant lower body fat percentage, but this may simply reflect that individuals with lower body fat percentages felt freer to consume fat. Mean steps taken per day was 7631.7 steps but only $16 \%$ of participants met healthy PA recommendations despite participating in daily structured exercise. All participants' diets met Dietary Guidelines for macronutrient distribution, but $80 \%$ were deficient in calcium, $100 \%$ were deficient in dietary vitamin $\mathrm{D}$, and $87 \%$ were deficient in fiber. Sample size was small, so it was difficult to reach statistical significance, despite seeing clinical significance.

Conclusions: Recommend working toward healthy PA recommendations for all age groups by decreasing time in sedentary activity. Recommend increasing vitamin A and D fortified dairy products and high-fiber foods, and consider dietary supplementation, especially for calcium, vitamin D, and fiber.

Keywords: Prader-Willi syndrome; diet; exercise; body composition; BMI; body fat; developmental disability

Received: 3 March 20 8; Revised: I May 20।8; Accepted: 7 May 20।8; Published: 18 June 2018

$\mathrm{M}$ uch of the research in Prader-Willi syndrome (PWS), especially in the United States, has been conducted with children and young adults, with few studies including adults beyond the age of 35. The focus of this study is adults with PWS and the associations between body composition, diet, physical activity (PA), and walking a timed distance. PWS was first described in literature in 1956 (1) and has a reported prevalence rate from 1 in 20,000 to 1 in 10,000 live births (2), with similar prevalence for gender (3), ethnicity and 
socioeconomic level. PWS is due to the loss of expression of several genes on chromosome 15 (2). Untreated PWS is characterized by uncontrolled eating, obesity, low lean body mass, low PA, mild to moderate intellectual disabilities, hypotonia, hypogonadism, short stature, and behavioral challenges (4), along with inability to vomit, skin picking, and lowered sensitivity to temperature and pain (5). Behavioral and psychiatric problems are also present and interfere most with quality of life in adolescence and adulthood (2).

Hypothalamic dysfunction is a factor in PWS and can result in central hypothyroidism, central adrenal insufficiency, growth hormone (GH) deficiency, and hypogonadotropic hypogonadism (6). Individuals with PWS typically present with lethargy, delayed motor development, decreased motor competencies, lower cognitive function, and behavioral challenges (2). GH treatment normalizes height $(7,8)$ and improves body composition, but it does not normalize body composition (7-9). Treatment with $\mathrm{GH}$ results in lower fat mass and higher lean mass (10), which can improve resting metabolic rate.

Resting metabolic rate is lower in individuals with PWS. Individuals with PWS have a low energy expenditure (11), with caloric needs as much as $20-40 \%$ less than individuals without the syndrome $(12,13)$. The best predictor of resting metabolic rate is fat-free mass (11) and body mass (14). Low lean mass and reduced PA are factors in low energy expenditure (12).

Morbidity in PWS is six times higher than other intellectual disabilities (15), with the mortality rate reported as $3 \%$ per year across all ages $(16,17)$ and up to $7 \%$ per year in those over 30 years of age (16). Early diagnosis of PWS and prevention of overweight are key factors in preventing early causes of death (18). Obesity is recognized as the main risk factor for death across all age groups (19). Adults are prone to premature death from cardiovascular disease, pulmonary problems, and type 2 diabetes $(2,20)$. Excess fat mass appears to be less likely to develop metabolic complications in PWS than in typical cardiac or obese patients, which is due to individuals with PWS having reduced visceral fat mass (8). The severity of obesity can be managed by early diagnosis, dietary restrictions, controlling access to food, regular exercise, appropriate behavioral counseling, and hormonal replacement (3).

Diet intervention, specifically kilocalorie (kcal) restriction, is a common treatment for preventing obesity in individuals with PWS. In adults with PWS, hyperphagia may be due to an abnormality of the satiety response to food intake $(21,22)$ or hormonal and neuroendocrine defects (23). Controlling food intake has contributed to the maintenance and prevention of weight gain and has been shown to improve anthropometric indices for individuals with PWS (24). Relying on cognitive controls to resist food can be almost impossible for individuals with PWS (5), so physical restraints, such as locked food cabinets and refrigerator, are utilized in the homes of individuals with PWS. In past studies, individuals following low kcal diets had lower BMIs and lower body fat percentages $(24,25)$. Restrictive diets, though, have been reported to result in shorter stature (26). In children with PWS, macronutrient intake has been reported to be within the U.S. Dietary Guideline recommendations, but fiber intake was less than $12 \mathrm{~g}$ per day (27). Another study in young children with PWS reported dietary deficiencies, including deficiencies in vitamin D, tocopherol, calcium, and iron (28). Individuals with PWS were more likely to take multivitamin, vitamins $\mathrm{C}$ and $\mathrm{D}$, calcium, and fish oil supplements (29).

Besides dietary intervention, PA can help in preventing obesity. Individuals with PWS tend to be less active than obese individuals and spend more time in sedentary activities and less time in lifestyle PA, but similar time in moderate to vigorous PA (30). Daily muscle training has been found to increase PA and lean body mass (31). Children and adults with PWS exhibit little vigorous PA and appear to perform few activities focused on improving muscle strength (32). In children with PWS, more PA has been associated with lower BMI and reduced engagement in self-injury behaviors, such as skin picking (33). It is unclear whether more sedentary time in individuals with PWS causes increased fat mass or whether higher fat mass restricts PA (34), but there is considerable hypoactivity in individuals with PWS despite long-term GH therapy and the absence of severe obesity (35). In children with PWS, muscle mass adequately responds to enhanced PA (36), which should improve body composition.

PA can be objectively measured using an accelerometer or a timed walk test. Accelerometers reliably measure movement in a period of time and have been used in many populations, including the PWS population. In PWS, accelerometers may underestimate energy expenditure and intensity of exercise due to reduced mean height, coordination of movements, lower maximum oxygen consumption, and increased mean weight (37). Besides accelerometers, the 6-minute walk test has been used with individuals with PWS (30). The 6-minute walk test has been used in multiple populations to measure overall fitness and is endorsed by the American Thoracic Society. The test is feasible and objective in assessing exercise capacity and may better reflect everyday activity capacity than lab tests (38). A walking distance of less than $350 \mathrm{~m}$ walked in the 6-minute walk is associated with increased mortality (39).

Lower amounts of PA and lean mass have made weight management difficult in individuals with PWS when compared to typically developing individuals (13, 40, 41). Individuals with PWS who reach or maintain a weight 
appropriate for their height remain over fat (12). Body composition in individuals with PWS resembles that of sedentary individuals and classic GH deficiency (42). The abnormal body composition phenotype in youth with PWS may be better described as sarcopenic (muscle loss), characterized by a reduced content of muscle mass and increased adipose tissue, whether or not they are receiving GH (43). The etiology of this abnormal body composition phenotype is likely multifactorial, including GH deficiency, decreased PA, autonomic nervous system dysfunction, primary muscle abnormalities, and pubertal delay (43).

Body composition, whether measured by BMI, body fat percentage, or waist/hip ratio, is an indicator of health risk in the typical population. For typical adults, BMI greater than 30 indicates obesity and health risk (44). Individuals with PWS typically have increased fat mass and decreased lean body mass $(9,40,42)$, with muscle mass decreased by $25-37 \%$ (9). Waist-to-hip ratio can be an indicator of increased risk of cardiovascular disease (45). For the general population, healthy waist-to-hip ratio recommendations are less than 0.9 for males and 0.85 for females (46). Increasing lean body mass should be a priority in the management of individuals with PWS (47).

When measuring body composition, dual-energy X-ray absorptiometry (DXA) has been considered the gold standards, but research has compared the accuracy of bioelectrical impedance analyzer (BIA) versus DXA. The correlation between DXA and BIA varies from reasonable to 'almost perfect' and is partly affected by the formula used with BIA (48-50). Studies have shown that BIA is a valid instrument for patients with a BMI up to $34 \mathrm{~kg} / \mathrm{m}^{2}$ (51), but the correlation decreases with a BMI greater than $35 \mathrm{~kg} / \mathrm{m}^{2}$ (52). The differences between BIA and DXA increased with the waist-to-hip ratio and the differences were higher in males than females (52). DXA measurements are challenging for participants aged 6 months to 5 years because the test subject must remain still during the procedure (53). This would also be a consideration for attempting measurements in participants who are developmentally disabled.

Choosing a BIA equation that is adapted to the population being studied continues to be a limiting factor of BIA (51). BIA has been used in many populations, including PWS. One PWS study showed a mean body fat percentage of $45.9 \%$, with no significant correlation between gender or genotype (54).

The purpose of this study was to determine associations between body composition, PA, diet, and walking a timed distance in adults with PWS, to determine nutritional adequacy of diets, and to take a snapshot of individuals throughout the aging process, by including older adults as well as young adults. The long-term objective of this study is to improve the quality of life of individuals with PWS by informing individuals and caregivers about the importance of PA and diet on quality of life throughout the lifespan, and to provide preliminary data regarding aging with PWS.

Specific Aim 1: Determine the association between PA measures (accelerometer data and activity logs) and body composition/obesity measures (BMI, waist/hip measurements, and body fat percentage) in individuals with PWS.

Specific Aim 2: Assess the association between body composition and the macronutrient distribution (percent carbohydrate, fat, and protein) of dietary intake.

Specific Aim 3: Determine the association between the ability to walk a timed distance (meters walked in 2 and $6 \mathrm{~min}$ ), using the walk test, and PA measures (accelerometer and activity log data) for individuals with PWS.

Specific Aim 4: Assess the adequacy of dietary intake, as a categorical variable of did/did not meet, of individuals with PWS, compared with dietary reference intakes.

\section{Present investigation}

\section{Methods}

Adults with PWS across the state of Oklahoma were recruited for participation. Contact was attempted by presenting the study at the Oklahoma PWS Association conference, sending e-mails to the Oklahoma PWS Association membership list, and through word of mouth. Participation was limited to individuals aged 18 and older. Consent was obtained from guardians and assent from the individuals participating in the study. Data collection involved obtaining anthropometric measurements, body composition, a walk test, PA measurements, food intake information, and a brief medical history. This study was approved by the University of Oklahoma Health Sciences Center Institutional Review Board.

\section{Anthropometric measurements}

Anthropometric measurements included: (1) height, measured using a metric stadiometer to the nearest $0.1 \mathrm{~cm}$, and (2) weight, using the weight measurement provided by the BIA, which reports weight to the nearest $0.1 \mathrm{~kg}$.

\section{Body composition}

Body composition was measured using the Tanita TBF-300A BIA and waist-to-hip ratio. Body fat analysis was measured with foot-to-foot bioelectrical impedance. Waist-to-hip ratio was assessed by measuring the waist circumference above the pelvic bone and the hip circumference at the widest point in the hip area. A metric fiberglass tape was used to prevent stretch of the instrument, and the measurements were made to the nearest $0.1 \mathrm{~cm}$. 


\section{Walk test}

The walk test followed the American Thoracic Society guidelines (38). When the walk test was completed indoors, the longest possible track with the least number of turns was utilized. When the walk test was completed outdoors, the participant set the pace and the researcher walked near the participant pushing a distance measuring wheel. Distance was measured at 2 and $6 \mathrm{~min}$. The time was measured by the stopwatch feature on a smart phone, and distance was measured using a measuring wheel.

\section{Physical activity measurements}

The ActivPal ${ }^{\circledR}$ accelerometer was used to collect information about movement in the form of steps per day and position, standing versus sitting/lying. The accelerometer was worn in the middle of the right thigh for up to 7 days, with a goal of a minimum of 4 days of usable data. The accelerometer was made waterproof by placing it in an extra-large finger cot and adhering it to the thigh using a piece of Tegaderm ${ }^{\circledR}$ transparent film dressing. Caregivers were instructed to check the accelerometer daily for waterproofing and were educated on how to reapply Tegaderm ${ }^{\circledR}$ as needed. A PA log was completed by caregivers at a time corresponding to the wearing of the accelerometer to aid in interpretation of activity registered on the accelerometer.

\section{Food intake}

Each participant's caregiver was asked to keep a detailed 3-day food and beverage diary. Food diary information was entered into FoodWorks ${ }^{\circledR}$ (55) nutrient analysis software, and intake information was compared to the Dietary Reference Intake for the appropriate gender and age. The macronutrient distribution was also obtained using FoodWorks ${ }^{\circledR}$.

\section{Medical history}

A brief medical history was completed by the guardian or caregiver using a questionnaire. The questionnaire included genotype of PWS, GH usage, medications, and comorbidities. The medical history provided information on confounders for statistical analyses.

\section{Data analysis}

Statistical analysis was completed using the SAS program. Linear regression analysis was used for Specific Aims 1, 2, and 3. Logistic regression was used for Specific Aim 4. Linear regression was used to test the association between total energy intake and body fat. Age, gender, height in centimeters, average daily steps, and weight in kilograms were all considered possible confounders and were examined in the model. All statistical tests were conducted assuming a $10 \%$ chance of a type 1 error.

\section{Results}

With approximately 100 known cases of PWS in Oklahoma (56), we estimate the adult population to be 60 or fewer individuals. Nineteen individuals chose to participate in the study, consisting of 11 males and 8 females. Participant characteristics are shown in Table 1.

Age range for participants was 18-62 years. BMI ranged from 20.9 to 35.0 among males and 19.5-34.9 among females. Steps were averaged for each individual who had at least 4 days of usable data. Average steps per day measured by the accelerometer were 7325.4 (3844.3-11338.8) for males and 7894.29 (3844.3-18769.0) for females. Body fat percentage range was 17.3-31.6 for males and 16.6-41.9 for females. Waist-to-hip ratio was $0.81-1.68$ for males and 0.78-0.99 for females.

When sorting the data by age groups over the adult spectrum (see Table 2), it appears that BMI, body fat percentage, and waist-to-hip ratio were higher for those over 40 years. Average steps were similar for the young adults (up to 30 years) and the older adults (over 40 years), but distance walked in both the 2- and 6-minute walk tests was about $20 \%$ less in those over 30 years compared to those under 30 years. The changes from the young adults ( $\leq 30$ years) to the older adults ( $>30$ years) may be the result of aging, or that interventions were not in place early in life for older adults to help attain a healthy weight or PA level.

Specific Aim 1: Of the participants, 50\% met the World Health Organization guidelines (46) for waist-to-hip ratio for decreased health risk (four males and five females). When adjusted for BMI, age, and gender, waist-to-hip

Table 1. Descriptive characteristics of participants

\begin{tabular}{lcccccc}
\hline Participants & $\mathrm{N}$ & $\begin{array}{c}\text { Average age } \\
\text { (years) } \pm \text { SEM }\end{array}$ & $\begin{array}{c}\text { Average } \\
\text { BMI } \pm \text { SEM }\end{array}$ & $\begin{array}{c}\text { Average } \\
\text { steps/day } \pm \text { SEM }\end{array}$ & $\begin{array}{c}\text { Average body fat } \\
\text { percentage } \pm \text { SEM }\end{array}$ & $\begin{array}{c}\text { Average waist/hip ratio } \\
\pm \text { SEM }\end{array}$ \\
\hline All & 19 & $34.5 \pm 4.3$ & $26.7 \pm 1.26$ & $7631.7 \pm 1171$ & $26.8 \pm 1.7$ & $0.93 \pm 0.07$ \\
Male & $1 \mathrm{I}$ & $35.1 \pm 3.9$ & $27.4 \pm 1.58$ & $7325.4 \pm 1173.6$ & $25.0 \pm 1.44$ & $0.97 \pm 0.09$ \\
Female & 8 & $34.6 \pm 4.83$ & $25.7 \pm 2.19$ & $7894.3 \pm 2021.2$ & $27.1 \pm 3.48$ & $0.85 \pm 0.03$ \\
Typical ideals & & & $18.5-24$ & 10,000 & Varies & 0.9 male \\
& & & & & & 0.85 female \\
\hline
\end{tabular}

SEM, standard error of the mean.

'Typical ideals': normal BMI range, steps per day (62), waist-to-hip (46). 
Table 2. Descriptive data by age group

\begin{tabular}{lccc}
\hline & I $8-30$ years old $(n=8) \pm$ SEM & 30-40 years old $(n=6) \pm$ SEM & Over 40 years old $(n=5) \pm$ SEM \\
\hline BMI & $27.99 \pm 2.27$ & $23.61 \pm 1.02$ & $30.50 \pm 2.08$ \\
Average body fat \% & $26.40 \pm 3.26$ & $23.87 \pm 1.73$ & $30.80 \pm 2.93$ \\
Waist-to-hip ratio & $0.88 \pm 0.03$ & $0.90 \pm 0.03$ & $1.01 \pm 0.20$ \\
(Male and Female) & M: $0.96 \mathrm{~F}: 0.82$ & M: $0.90 \mathrm{~F}: 0.89$ & M: $1.08 \mathrm{~F}: 0.91$ \\
Average steps per day & $8243.19 \pm 2237.1$ & $5411.51 \pm 1379.84$ & $8379.74 \pm 1660.86$ \\
2-minute walk $(\mathrm{m})$ & $148.75 \pm 16.09$ & $119.00 \pm 7.30$ & $99.20 \pm 18.38$ \\
6-minute walk $(\mathrm{m})$ & $447.13 \pm 41.60$ & $348.17 \pm 20.93$ & $349.00 \pm 38.44$ \\
\hline
\end{tabular}

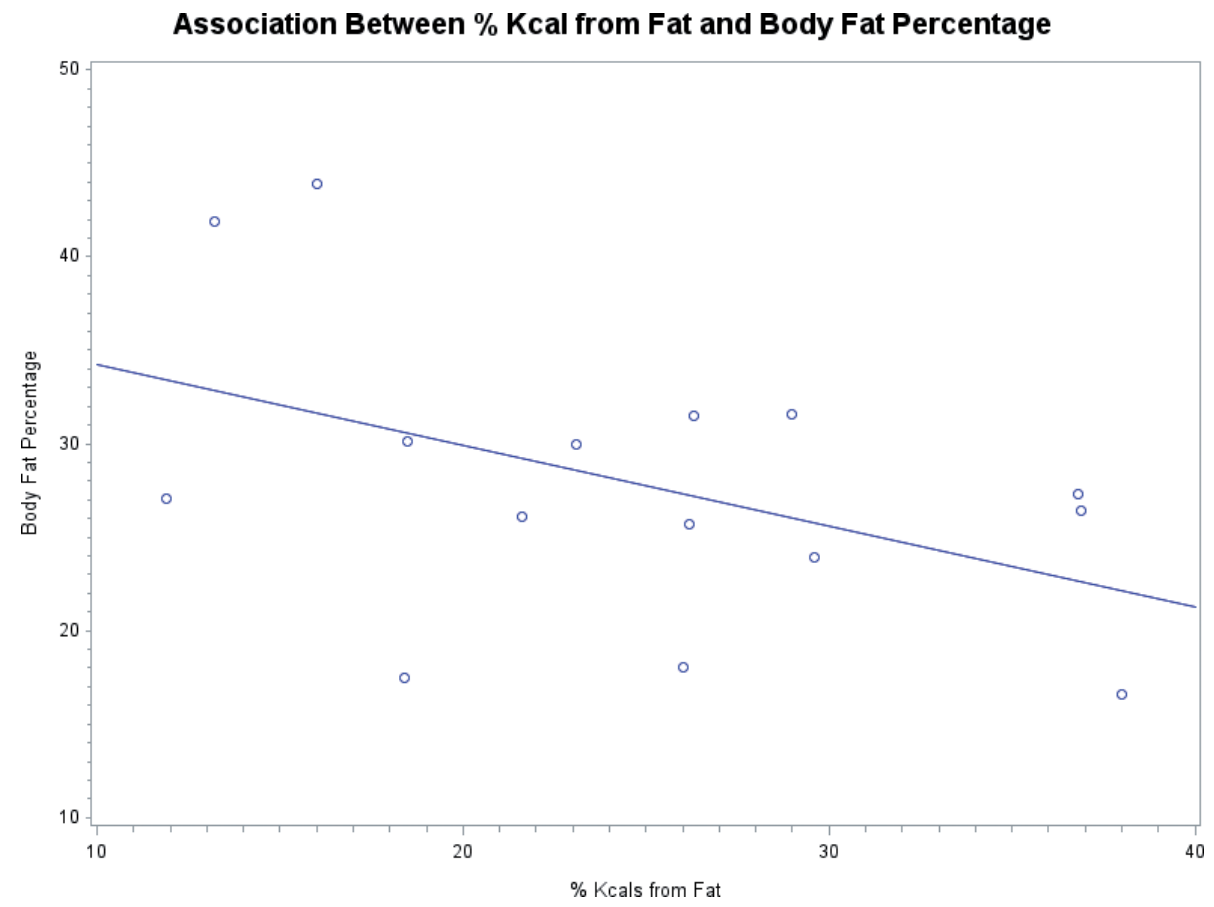

Fig. 1. Association between Body Fat Percentage and Average Dietary Fat Intake.

ratios were not associated with $\mathrm{PA}(p=0.7481, t=-0.33$, $\mathrm{df}=1)$. In addition, there was no evidence of interaction between waist-to-hip ratio and $\operatorname{BMI}(p=0.4067, t=-0.87$, $\mathrm{df}=1)$, waist-to-hip ratio and gender $(p=0.4936$, $t=-0.71, \mathrm{df}=1)$, or waist-to-hip ratio and age $(p=0.3920$, $t=0.89, \mathrm{df}=1)$. Adjusted for BMI, age, and gender, body fat percentage was not associated with PA $(p=0.1496$, $t=-1.55$, df $=1$ ). In addition, there was no evidence of an interaction between body fat percentage and BMI ( $p=0.9177, t=-0.11, \mathrm{df}=1)$, body fat percentage and age $(p=0.5474, t=0.62, \mathrm{df}=1)$, or body fat percentage and gender $(p=0.0594, t=-2.13, \mathrm{df}=1)$.

Specific Aim 2: Dietary information was kept by 15 of the 19 participants. There was no evidence of age or gender confounding the statistical model or effect modification in the relationship between body fat percentage $(\mathrm{BF} \%)$ and the percent of kcals from either carbohydrates, protein, or fat. Percent of kcals from carbohydrates was not associated with $\mathrm{BF} \%(p=0.2187, t=1.29$, df $=1)$. There was no association between $\mathrm{BF} \%$ and percent of kcals from protein $(p=0.1710, t=1.45$, df $=1)$. Percent of kcals from fat was significantly negatively associated with $\mathrm{BF} \%(p=0.0800, t=-1.90, \mathrm{df}=1)($ Fig. 1$)$.

Specific Aim 3: The ability to walk a timed distance, as measured by the 2- and 6-minute walk tests, was not significantly associated with average daily PA, as measured by the average steps per day, for the 2 -minute walk test ( $p=0.1525, t=1.54$, df $=1$ ) or the 6-minute walk test ( $p=0.1341, t=1.62$. df $=1)$. While not at a level of significance, there did appear to be a positive association between PA and distance walked in the walking tests (Fig. 2). Age is negatively correlated with distance walked during a 2-minute walk ( $p=0.0034)$, with distance walked decreasing 2.0 steps 
Association Between 6-Minute Walk Distance (Meters)and Average Steps

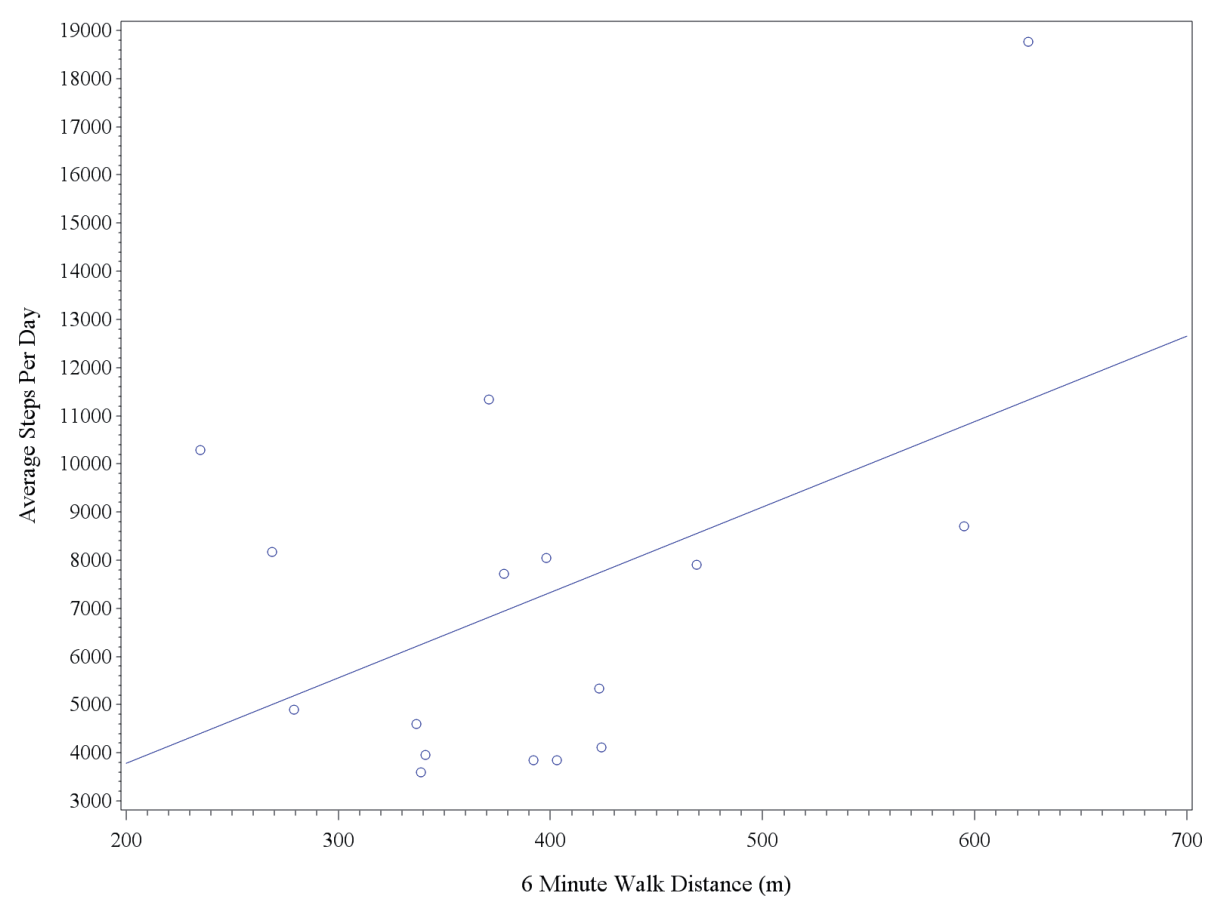

Fig. 2. Association between Average Steps and 6-Minute Walk Test.

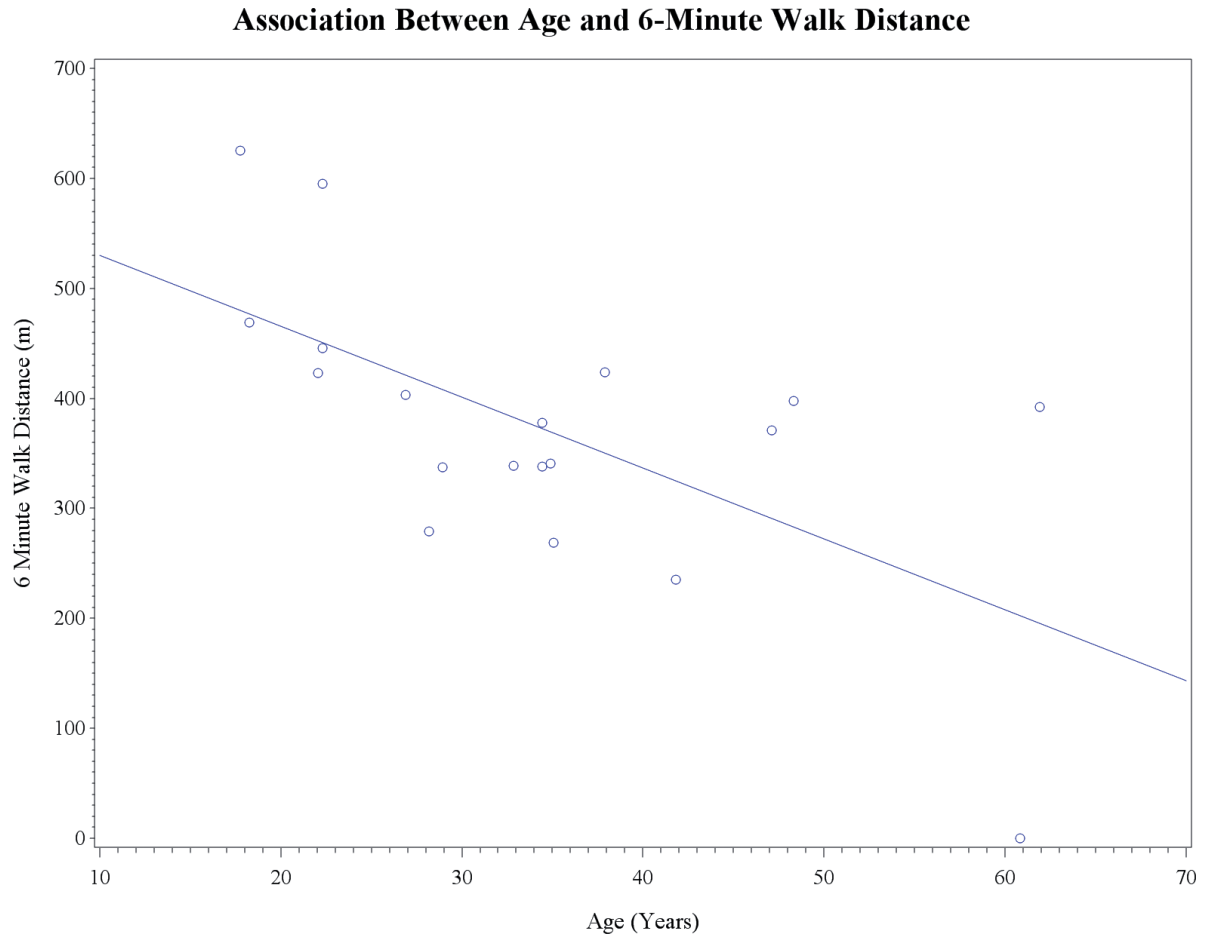

Fig. 3. Association Between Age and 6-Minute Walk Distance.

(95\% CI: $0.8,3.2)$ for each 1 -year increase in age. Fig. 3 shows age is negatively correlated with distance walked during the 6-minute walk test $(p=0.0029)$, with distance walked decreasing 6.8 steps $(95 \% \mathrm{CI}: 2.7,10.8)$ for each 1-year increase in age. Gender was not associated with a decrease in distance walked on a 2 -minute walk $(p=0.5397, t=0.63, \mathrm{df}=1)$ or a 6 -minute walk $(p=0.9567, t=0.06, \mathrm{df}=1)$. 
Table 3. Number of participants taking dietary supplementation

\begin{tabular}{lcccc}
$\begin{array}{l}\text { Vitamin } \\
\text { and mineral } \\
\text { supplement }\end{array}$ & $\begin{array}{c}\text { Number of } \\
\text { participants } \\
(n=19)\end{array}$ & $\begin{array}{c}\text { Participants } \\
\text { 18-29 years } \\
\text { old }(n=8)\end{array}$ & $\begin{array}{c}\text { Participants } \\
30-40 \text { years } \\
\text { old }(n=6)\end{array}$ & $\begin{array}{c}\text { Participants } \\
\text { over 40 years } \\
\text { old }(n=5)\end{array}$ \\
\hline MV & 10 & 3 & 4 & 3 \\
Calcium & 6 & 1 & 4 & 1 \\
Vitamin D & 5 & 1 & 2 & 2 \\
\hline
\end{tabular}

Table 4. F-tests and associated $p$-values for suspected confounders and suspected effect modifiers in the association between total energy intake and body fat

\begin{tabular}{lcc}
\hline Variable and test & $\begin{array}{c}\text { Type 3 } \\
\text { F-statistic }\end{array}$ & $p$ \\
\hline Gender effect modifier & 6.27 & $0.0293^{\mathrm{a}}$ \\
Average steps effect modifier & 0.12 & 0.7349 \\
Average steps covariate & 0.57 & 0.4658 \\
Height in centimeter effect modifier & 2.44 & 0.1463 \\
Height in centimeter covariate & 0.11 & 0.7480 \\
Age (years) effect modifier & 0.19 & 0.6681 \\
Age (years) covariate & 0.40 & 0.5412 \\
Weight (kg) effect modifier & 0.01 & 0.9150 \\
Weight (kg) covariate & 11.19 & $0.0058^{\mathrm{b}}$ \\
\hline
\end{tabular}

${ }^{\mathrm{a}} \mathrm{Gender}$ significant effect modifier, stratified by gender; ${ }^{\mathrm{b} W e i g h t}(\mathrm{~kg})$ did show evidence of confounding and was left in the final model.

Specific Aim 4: Calcium recommendations based on the U.S. recommended dietary allowances [RDA (57)] (based on age and gender) were met by $20 \%(3 / 15)$ from diet alone (95\% CI: 4.33\%, 48.09\%); gender, BMI, and $\mathrm{BF} \%$ were not associated with meeting calcium recommendations. Sodium recommendations from the U.S. Dietary Guidelines (58) were met by $66.67 \%$, whose average sodium intake was below 2,300 mg daily ( $95 \% \mathrm{CI}: 38.4 \%$, $88.2 \%$ ); gender, $\mathrm{BMI}$, and $\mathrm{BF} \%$ were not associated with meeting sodium recommendations. Fiber guidelines based on the U.S. Daily Value (59) were met by $13.33 \%$ (2/15) (95\% CI: 1.66\%, 40.46\%); gender, BMI, and $\mathrm{BF} \%$ were not associated with meeting fiber guidelines. None of the participants with dietary intake information met vitamin D recommendations from diet alone. Gender $\left(X^{2}=0.2679, \mathrm{df}=1, p=0.6048\right), \mathrm{BMI}\left(X^{2}=0.0 .3673, \mathrm{df}\right.$ $=1, p=0.5445)$, and $\mathrm{BF} \%\left(X^{2}=0.0057, \mathrm{df}=1, p=0.9398\right)$ were not associated with meeting calcium dietary reference intakes. Gender $\left(X^{2}=0.1339\right.$, df $\left.=1, p=0.7144\right)$, BMI $\left(X^{2}=0.0131\right.$, df $\left.=1, p=0.9089\right)$, and $\mathrm{BF} \%$ $\left(X^{2}=0.1908, \mathrm{df}=1, p=0.6622\right)$ were not associated with meeting sodium dietary reference intakes. Gender $\left(X^{2}=2.0192, \mathrm{df}=1, p=0.1553\right), \mathrm{BMI}\left(X^{2}=1.4566, \mathrm{df}\right.$ $=1, p=0.2275)$, and $\mathrm{BF} \%\left(X^{2}=0.6012, \mathrm{df}=1, p=0.4381\right)$ were not associated with meeting fiber dietary reference intakes. This analysis addresses dietary intake of these nutrients, but some participants took these nutrients in supplement form (Table 3).

Table 4 shows $p$-values with associated $F$-tests for tested covariates with total energy intake (kcals), along with tests for effect modification. Gender was a significant effect modifier, so the final model was stratified by gender status $(p=0.0293)$. In addition, weight in kilograms showed evidence of a confounding association and was adjusted for in the final model $(p=0.0058)$. After adjusting for the individuals weight $(\mathrm{kg})$, total energy intake (kcals) was not associated with body fat, among males $(F=0.33$, $p=0.5943)$. However, adjusted for weight $(\mathrm{kg})$, total energy (kcal) was associated with body fat, among females (Fig. 4). After adjusting for weight, females showed a body fat decrease of $1 \%$ for each $100 \mathrm{kcal}$ increase in total energy intake (95\% CI: $0.269 \%, 2.39 \%, p=0.0234)$.

The study looked at comorbidities as possible confounders (Table 5). Almost 50\% of participants did not have any comorbidities. Diabetes and hypertension were equally divided between the age groups, with only one participant from each age group having each disease. Of the six individuals with diabetes or hypertension, four were classified as obese (BMI > 30), and the remaining two individuals were overweight $(\mathrm{BMI}>24)$. The other noted comorbidities did not have trends related to age or BMI.

\section{Discussion}

People with PWS are living longer, but there is a dearth of information about aging with PWS. This cross-sectional study looks at aging in PWS with specific emphasis on body composition, diet, and exercise. This study provides preliminary data for a longitudinal study on changes occurring with aging in PWS. We were able to capture about $30 \%$ of the estimated adult population in Oklahoma, with a wide range of ages from 18 to 62 years. This is unique because most studies in PWS are with children and rarely include individuals beyond 35 years of age.

While the mean BMI of 26.7 is above the ideal range for health in typically developing individuals, it is lower than many previous studies in PWS. Of our participants, $37 \%$ were within the recommended BMI range of $18.5-$ 24. BMI may underestimate adiposity in individuals with PWS (34), but it does offer a comparison within the PWS population. Our study showed slightly lower waist-to-hip ratios than Lin et al. (54) but higher than findings by Hoybye for men (60). A possible reason for improved BMI and waist-to-hip ratio is earlier intervention for diet and exercise for younger individuals, but those over 30 have often reached morbid obesity at some time in their lives. Only one individual over 35 years had a BMI within normal range, but all were below 35 , which shows that intervention later in life is also effective for improving these health risk indicators. 


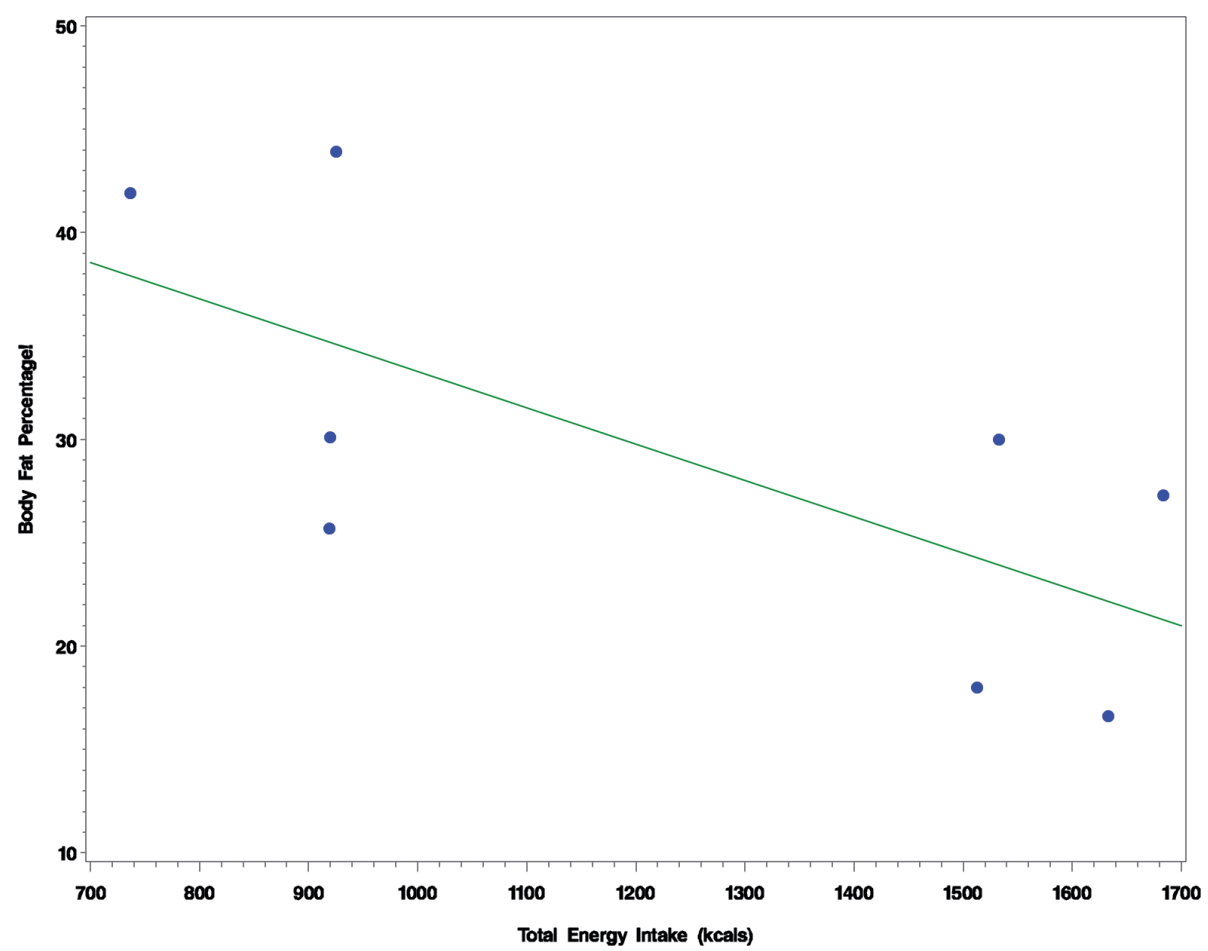

Fig. 4. Association between Body Fat Percentage and Total Energy Intake Adjusted for Weight (kg), Among Females with PWS. $\left(p=0.0234, \beta_{\text {kcal }}=-0.01\right)$.

Table 5. Number of participant reporting diagnoses in addition to PWS

\begin{tabular}{|c|c|c|c|c|}
\hline & $\begin{array}{c}\text { Number of } \\
\text { participants } \\
(n=19)\end{array}$ & $\begin{array}{c}\text { Participants } \\
\text { under } 30 \\
\text { years }(n=8)\end{array}$ & $\begin{array}{c}\text { Partici- } \\
\text { pants30-40 } \\
\text { years }(n=6)\end{array}$ & $\begin{array}{l}\text { Participants } \\
\text { over } 40 \text { years } \\
\quad(n=5)\end{array}$ \\
\hline $\begin{array}{l}\text { No } \\
\text { comorbidities }\end{array}$ & 10 & 4 & 4 & 2 \\
\hline Hypertension & 3 & I & I & I \\
\hline $\begin{array}{l}\text { Diabetes and } \\
\text { prediabetes }\end{array}$ & 3 & I & I & I \\
\hline $\begin{array}{l}\text { Hypercholes- } \\
\text { terolemia }\end{array}$ & 2 & 0 & 2 & 0 \\
\hline Scoliosis & I & I & 0 & 0 \\
\hline
\end{tabular}

Information obtained from medical history questionnaire.

Table 6. Macronutrient distribution in diet as a percentage of kcalories (energy)

\begin{tabular}{lll}
\hline & Study findings & U.S. Dietary Guidelines \\
\hline Carbohydrate & $39-60 \%$ & $45-65 \%$ \\
Protein & $15-31 \%$ & $10-35 \%$ \\
Fat & $12-38 \%$ & $20-35 \%$ \\
Sodium & $2,273 \mathrm{mg} \pm 213.9$ & $<2,300 \mathrm{mg}$ \\
Fiber & $16.9 \mathrm{gm} \pm 1.2$ & $25 \mathrm{gm}$ (U.S. daily value)
\end{tabular}

Note: U.S. Dietary Guidelines (58).

Findings are the percent of kcals from carbohydrate, protein, and fat as compared with average daily kcals consumed by each participant.
Our study showed much lower body fat percentage than most studies $(12,42,44,60,61)$. Possible reasons for this might be: (1) earlier diagnosis and intervention for those under 30 years, (2) stronger efforts toward maintaining body weight within recommended guidelines for all age groups, (3) emphasis for all age groups to incorporate exercise into daily routines, and (4) use of GH in younger individuals with PWS.

Despite typically lower caloric intake, macronutrient intake from diet, shown in Table 6, was within or nearwithin U.S. Dietary Guidelines (58). Other studies in children with PWS also found similar intake ranges $(27,29)$. Overall, our study with adults was comparable to these findings in children but ranged higher in fat and protein, and lower in carbohydrate. The statistically significant finding that higher average intake of fat (as a percent of total kcals) may be associated with body fat percentage may simply reflect that individuals with lower body fat percentages felt freer to consume fat. When individuals are overweight, they may have a tendency to limit fat intake due to higher caloric density.

Fiber intake was below recommendations based on the U.S. Daily Value (59). While this is typical for American intake patterns, it is not ideal. Because individuals with PWS often take medications that increase constipation, it is important to encourage healthy fiber and fluid intake. An additional difficulty in obtaining adequate fiber is that high-fiber foods tend to be more expensive and most of 
our participants are dependent on government assistance for their food dollar.

Our study found dietary deficiencies in vitamin D (3.17 $\mathrm{mcg} \pm 0.49)$ and calcium $(805.6 \mathrm{mg} \pm 82.1)$ which is similar to previous studies among children with PWS. Most participants, though, took a multivitamin, vitamin D, and/or calcium supplements. Because many individuals were low in vitamin D and calcium intake, it is important to consider meeting the need through supplementation, although sun exposure is an easy, inexpensive consideration for a source of vitamin D.

Individuals with PWS have been found to be less active than obese individuals and spend less time in light and lifestyle PA (30). Exercise is important for maintaining lean body mass, which impacts mobility, metabolism, and health risk. While this study had three individuals meeting or exceeding the 10,000 step recommendations (62) for health, there were also participants who did not reach an average of 5,000 steps daily. Despite most participants including at least $30 \mathrm{~min}$ of structured exercise daily, they still failed to meet the 10,000-step recommendation. This indicates that structured exercise is only part of the goal, and that limiting sedentary time is also important. Walking a distance of less than $350 \mathrm{~m}$ in the 6-minute walk test is associated with increased mortality (39) for the typical population. Participants in this study walked further than $350 \mathrm{~m}$, on average, indicating physical capacity adequate for decreased mortality risk based on standards for the typical population.

While most results in this study did not show statistical significance due to small sample size, there were several areas of clinical importance. The improved BMI and body fat percentage compared to studies in the past show that current levels of intervention, such as nutrition education and the assistance of state of Oklahoma programs, may be helping prevent obesity in individuals with PWS. Overall, individuals with PWS in Oklahoma are doing fairly well with PA, but efforts need to continue toward meeting the activity recommendations of 10,000 steps daily (62). This can be accomplished by incorporating formal exercise, but helping individuals with PWS stay active through the day is also important. Ways to do this might include exercise breaks at work and limiting sitting or sleeping during the day. Dietary deficiencies indicate a need to focus on sources of calcium, vitamin D, and fiber along with considering supplementation.

Limitations of the study were sample size, limited documentation of dietary intake, and use of BIA rather than DXA. While we captured over $30 \%$ of the adult population, the population of individuals with PWS is fairly small. While we do not hope for a large population of individuals with PWS, expanding the study to other states would increase the pool of potential participants. Dietary documentation was limited, with some individuals having less than 3 days of usable data. One difficulty with documentation is that most adult participants live in homes where they are cared for by staff. This means there are various caregivers throughout the day being tasked with keeping the documentation. For future studies, researchers should try to limit the amount of documentation required from staff members or explore other avenues to encourage more accurate completion of the documentation.

Body fat percentage was measured with foot-to-foot bioelectrical impedance. The researcher acknowledges that DXA is considered the standard for measurement by many, but DXA was not easily available to participants around the state of Oklahoma, and DXA to DXA has not proven to be correlated. Bioelectrical impedance analysis offered a portable solution to collected body fat percentage data without excessive cost or travel for the participant.

One concern prior to the start of the study was that the tendency toward skin picking and obsessive-compulsive disorder among individuals with PWS might limit the ability to wear the accelerometer for at least 4 days for data collection. This turned out to be unfounded, with only two individuals refusing to wear the accelerometer for at least 4 days and one individual being agitated during data collection, so the accelerometer was not attempted.

A possible bias of the study is that approximately half of the participants in this study were clients of the primary researcher prior to the study. Of the participant group, 15 had received nutritional services from a dietitian prior to the study; it is assumed that this did not impact results. It should be clarified that although these individuals and their staff received intervention and education regarding nutrition, the dietitian can only increase awareness of the needed diet and PA information but cannot enforce compliance.

An assumption made for dietary recalls was that it was assumed that documentation was a true reflection of actual intake. Difficulties with this could be participants' compulsion to sneak food, which is part of the syndrome. Individuals with PWS have been known to sneak food, such as a jar of peanut butter, and eat it without staff knowledge.

\section{Conclusions}

The only significant associations found in this study were between fat intake for women and body fat percentage, and kcalorie intake and body fat percentage. This is believed to represent individuals with acceptable BMI and $\mathrm{BF} \%$ feeling freer to consume more fat and kcalories in their diets. Body fat percentage is lower in adults with PWS in Oklahoma compared to previous studies. Adults with PWS were deficient in calcium, vitamin D, and fiber, 
which could be combatted by adding vitamin $\mathrm{A}$ and $\mathrm{D}$ fortified dairy and whole grain products to the diet, along with considering vitamin, mineral, and fiber supplementation. PA in adults of all ages with PWS is below healthy guidelines and could be increased by limiting sedentary time throughout the day, as well as ensuring at least 30 min of structured exercise daily.

\section{Acknowledgements}

The authors thank the participants, their families, and caregivers.

\section{Conflict of interest and funding}

Corresponding author works as a consultant dietitian with individuals with Prader-Willi Syndrome in Oklahoma through the Department of Human Services/ Developmental Disabilities Division. No other authors had conflict of interest. This research did not receive any funding support from funding agencies in the public, commercial, or not-for-profit sectors.

\section{Ethics and consent}

This project was approved by the University of Oklahoma Health Sciences IRB. Consent was obtained from guardians and assent was obtained from participants.

\section{References}

1. Prader A. Die Nebennieren-Krankheiten Im Kindesalter. Ann Paediatr 1956; 186: 94-100.

2. Cassidy S, Schwartz S, Miller J, Driscoll D. Prader-Willi syndrome. Genet Med 2012; 14(1): 10-26.

3. Goldstone A, Holland A, Hauffa B, Hokken-Koelega A, Tauber M. Recommendations for the diagnosis and management of Prader-Willi syndrome. J Clin Endocrinol Metab 2008; 93: 4183-97.

4. Whittington J, Holland A, Webb T, Butler J, Clarke D, Boer H. Cognitive abilities and genotype in a population-based sample of people with Prader-Willi syndrome. J Intellect Disabil Res 2004; 48: 172-87.

5. McAllister C, Whittington J. A short clinical overview of Prader-Willi syndrome. Clin Obes 2011; 1: 184-8.

6. Irizarry K, Miller M, Freemark M, Haqq A. Prader-Willi syndrome: Genetics, metabolomics, hormonal function, and new approaches to therapy. Adv Ped 2016; 63: 47-77.

7. Lindgren A, Lindberg A. Growth hormone treatment completely normalizes adult height and improves body composition in Prader-Willi syndrome: experience from KIGS. Horm Res 2008; 70(3): 182-7.

8. Lloret-Linares C, Faucher P, Coupaye M, Alilli R, Green A, Basedevant A, et al. Comparison of body composition, basal metabolic rate and metabolic outcomes of adults with Prader-Willi syndrome or lesional hypothalamic disease, with primary obesity. Int J Obes 2013; 37: 1198-203.

9. Reus L, Zwarts M, van Vlimmeren LA, Willemsen MA, Otten BJ, Nijhuis-van der Sanden MWG. Motor problems in Prader-Willi syndrome: a systematic review on body composition and neuromuscular functioning. Neurosci Biobehav Rev 2011; 35: 956-69.
10. Kuppens R, Bakker N, Siemensma E, Tummers-de Lind van Wijngaarden R, Donze S, Festen D, et al. Beneficial effects of GH in young adults with Prader-Willi syndrome: a 2-year crossover trial. J Clin Endocrinol Metab 2016; 101(11): 4110-16.

11. Ravussin E, Bogardus C. Relationship of genetics, age, and physical fitness to daily energy expenditure and fuel utilization. Am J Clin Nutr 1980; 49(suppl): 968-75.

12. Schoeller D, Levitsky L, Bandni L, Dietz W, Walczak A. Energy expenditure and body composition in Prader-Willi syndrome. Metabolism 1988; 37(2): 115-20.

13. Butler M, Theodoro M, Bittel D, Donnelly J. Energy expenditure and physical activity in Prader-Willi syndrome: comparison with obese subjects. Am J Med Genet A 2007; 143A(5): 449-59.

14. Lazzer S, Grugni G, Tringali G, Sartorio A. Prediction of basal metabolic rate in patients with Prader-Willi syndrome. Eur J Clin Nutr 2016; 70: 494-8.

15. Einfeld S, Kavanagh S, Smith A, Evans E, Tonge B, Taffe J. Mortality in Prader-Willi syndrome. Am J Ment Retard 2006; 111: $193-8$.

16. Whittington J, Holland A, Webb T, Butler J, Clarke D, Boer H. Population prevalence and estimated birth incidence and mortality rate for people with Prader-Willi syndrome in one UK Health Region. J Med Genet 2001; 38: 792-8.

17. Butler J, Whittington J, Holland A, Boer H, Clarke D, Webb T. Prevalence of, and risk factors for, physical ill-health in people with Prader-Willi syndrome: a population-based study. Dev Med Child Neurol 2002; 44: 248-55.

18. Butler M, Manzardo A, Heinemann J, Loker C, Loker J. Causes of death in Prader-Willi syndrome: Prader-Willi syndrome association (USA) 40-year mortality survey. Genet Med 2017; 19(6): 635-42.

19. Zipf W. Prader-Willi syndrome: the care and treatment of infants, children, and adults. Adv Pediatr 2004; 51: 409-34.

20. Butler M, Hanchett J, Thompson T. Clinical findings and natural history of Prader-Willi syndrome. 3rd ed. New York: Springer; 2006.

21. Holland A, Treasure J, Coskeran P, Dallow J, Milton N, Hillhouse E. Measurement of excessive appetite and metabolic changes in Prader-Willi syndrome. Int J Obes 1993; 17: 527-32.

22. Hinton E, Holland A, Gellatly M, Soni S, Patterson M, Ghatei $\mathrm{M}$, et al. Neural representations of hunger and satiety in Prader-Willi yndrome. Int J Obes 2006; 30: 313-21.

23. Goldstone A. Prader-Willi syndrome: advances in genetics, pathophysiology and treatment. Trends Endocrinol Metab 2004; 15: $12-20$.

24. Penner de Lima V, Emerich DR, Guedes de Mesquita ML, Paternez ACAC, Carreiro LRR, de Pina Neto JM, et al. Nutritional intervention with hypocaloric diet for weight contrl in children and adolescents with Prader-Willi syndrome. Eat Behav 2016; 21: 189-92.

25. Bonfig W, Dokoupil K, Schmidt H. A special, strict, fat-reduced, and carbohydrate-modified diet leads to marked weight reduction even in overweight adolescents with Prader-Willi syndrome (PWS). ScientificWorldJournal 2009; 9: 934-9.

26. Schmidt H, Pozza S, Bonfig W, Schwarz H, Dokoupil K. Successful early dietary intervention avoids obesity in patients with Prader-Willi syndrome: a ten-year follow-up. J Pediatr Endocrinol Metab 2008; 21(7): 651-5.

27. Miller J, Lynn C, Shuster J, Driscoll DJ. A reduced-energy intake, well-balanced diet improves weight control in children with Prader-Willi syndrome. J Hum Nutr Diet 2013; 26: 2-9. 
28. Lindmark M, Trygg K, Giltvedt K, Kolset S. Nutritient intake of young children with Prader-Willi syndrome. Food Nutr Res 2010; 54: 2112.

29. Rubin DA, Nowak J, McLaren E, Patino M, Castner DM, Dumont-Driscoll MC. Nutritional intake in children with Prader-Willi syndrome and non-congenital obesity. Food Nutr Res 2015; 29427.

30. Nordstrom M, Hansen BH, Paus B, Kolset SO. Accelerometerdetermined physical activity and walking capacity in persons with Down syndrome, Williams syndrome and Prader-Willi syndrome. Res Dev Disabil 2013; 34: 4395-403.

31. Schlumpf M, Eiholzer U, Gygax M, Schmid S, van der Sluis I, I'Allemand D. A daily comprehensive muscle training programme increases lean mass and spontaneous activity in children with Prader-Willi syndrome after 6 months. J Pediatr Endocrinol Metab 2006; 19: 65-74.

32. Rubin DA, Mowttapa M, Weiss J, Barrera-Ng A. Physical activity in children with Prader-Willi syndrome: a parents' perspective. Calif J Healh Promot 2012; 10(Special Issue: Obesity Prevention \& Intervention): 57-66.

33. Dykens E. Leisure activities in Prader-Willi syndrome: implications for health, cognition and adaptive functioning. J Autism Dev Disord 2014; 44(2): 294-302.

34. van Mil E, Westerterp K, Gerver W, van Marken Lichtenbelt W, Kester A, Saris W. Body composition in Prader-Willi syndrome compared with nonsyndromal obesity: relationship to physical activity and growth hormone function. J Pediatr 2001; 139: 708-14.

35. Eiholzer U, Nordmann Y, L'Allemand D, Schlumpf M, Schmid S, Kromeyer-Hauschild K. Improving body composition and physical activity in Prader-Willi syndrome. J Pediatr 2003; 142: 73-8.

36. Eiholzer U, Schlumpf M, Nordmann Y, I'Allemand D. Early manifestations of Prader-Willi syndrome: influence of growth hormone. J Pediatr Endocrinol Metab 2001; 14(Supp 6): 1441-4.

37. Hinckson E, Dickinson A, Water T, Sands M, Penman L. Physical activity, dietary habits and overall health in overweight and obese children and youth with intellectual disability or autism. Res Dev Disabil 2013; 34: 1170-8.

38. American Thoracic Society. ATS Statement: guidelines for the sixminute walk test. Am J Respir Crit Care Med 2002; 166: 111-17.

39. Rasekaba T, Lee A, Naughton M, Williams TJ, Holland AE. The six-minute walk test: a useful metric for the cardiopulmonary patient. Int Med J 2009; 39(8): 495-501.

40. Rubin DA, Cano-Sokoloff N, Castnner D, Judelson D, Wright P, Duran A, et al. Update on body composition and bone density in children with Prader-Willi syndrome. Horm Res Paediatr 2013; 79(5): 271-6.

41. Castner D, Tucker J, Wilson K, Rubin D. Patterns of habitual physical activity in youth with and without Prader-Willi syndrome. Res Dev Disabil 2014; 35(11): 3081-8.

42. Brambilla P, Bosio L, Manzoni P, Pietrobelli A, Beccaria L, Chiumelo G. Peculiar body composition in patients with Prader-Labhart-Willi syndrome. Am J Clin Nutr 1997; 65: 1369-74.

43. Orsso CE, Mackenzie M, Alberga AS, Sharma AM, Richer $\mathrm{L}$, Rubin DA, et al. The use of magnetic resonance imaging to characterize abnormal body composition phenotypes in youth with Prader-Willi syndrome. Metab Clin Exp 2017; 69: 67-75.

44. Theodoro MF, Talebizadeh Z, Butler MG. Body composition and fatness patterns in Prader-Willi syndrome: comparison with simple obesity. Obesity 2006; 14(10): 1685-90.

45. Klein S, Allison D, Heymsfield S, Kelley D, Leiel R, Nonas C, et al. Waist circumference and cardiometabolic risk: a consensus statement from Shaping America's Health: association for weight management and obesity prevention. Am J Clin Nutr 2007; 85(5): 1197-202.
46. World Health Organization. Waist circumference and waisthip ratio: report of a WHO expert consultation, Geneva, 8-11, December 2008. 2011. Contract No.: ISBN: 9789241501491.

47. van den Berg-Emmons R, Festen D, Hokken-Koelega A, Bussman J, Stam H. Everyday physical activity and adiposity in Prader-Willi syndrome. J Pediatr Endocrinol Metab 2008; 21(11): 1041-8.

48. Faria S, Faria O, Cardeal M, Ito M. Validation study of multi-frequency bioelectrical impedance with dual-energy X-ray absorptiometry among obese patients. Obes Surg 2014; 24: 1476-80.

49. Donini L, Poggiogalle E, del Balzo V, Lubrano C, Faliva M, Opizzi A, et al. How to estimate fat mass in overweight and obese subjects. In t J Endocrinol 2013; 2013: 285680.

50. Miller R, Chambers TL, Burns SP, Goddard MP. Validating InBody 570 Multi-frequency bioelectrical impedance analyzer versus DXA for body fat percentage analysis. Med Sci Sports Exerc 2016; 48(5S): 991.

51. Kyle U, Bosaeus I, De Lorenzo A, Deurenberg P, Elia M, Gomez J, et al. Bioelectrical impedance analysis - part 1: review of principles and methods. Clin Nutr 2004; 23: 1226-43.

52. Boneva-Asiova Z, Boyanov M. Body composition analysis by leg-to-leg bioelectrical impedance and dual-energy X-ray absorptiometry in non-obese and obese individuals. Diabetes Obes Metab 2008; 10: 1012-18.

53. Shepherd J, Heymsfield S, Norris S, Redman L, Ward L, Slater C. Measuring body composition in low-resoure settings across the life course. Obesity 2016; 24(5): 985-8.

54. Lin H, Chen M, Chuang C, Huang C, Niu D, Lin S. Assessment of body composition using bioelectrical impedance analysis in Prader-Willi syndrome. J Formos Med Assoc 2011; 110: 719-23.

55. FoodWorks. FoodWorks. Nutrient Analysis Software: the professional's choice. Available from: http://nutritionco.com/FoodWorks.htm. Accessed November 2016.

56. Prader-Willi Syndrome Association (USA). Prader-Willi Syndrome Statistics Available from: https://www.pwsausa.org/pwsstatistics/. Accessed December 2016.

57. United States Department of Agriculture. Recommended Dietary Allowances (RDA). Available from: https://www.nal. usda.gov. Accessed December 2016.

58. Office of Disease Prevention and Health Promotion. 2015 Dietary Guidelines. Available from: https:/www.health.gov/ dietaryguidelines 2015. Accessed December 2016.

59. U.S. Food and Drug Administration. Daily value. Available from: http://www.fda.gov. Accessed January 2017.

60. Hoybye C, Hilding A, Jacobsson H, Thoren M. Metabolic profile and body composition in adults with Prader-Willi syndrome and severe obesity. J Clin Endocrinol Metab 2002; 87(8): 3590-7.

61. Carrel A, Myers S, Whitman BY, Allen D. Growth hormone improves body composition, fat utilization, physical strength and agility, and growth in Prader-Willi syndrome: a controlled study. J Pediatr 1999; 134: 215-21.

62. Tudor-Locke C, Bassett Jr D. How many steps/day are enough? Preliminary pedometer indices for public health. Sports Med 2004; 34(1): 1-8.

\footnotetext{
*Susan G.Woods

University of Central Oklahoma,

100 N. University Drive, Edmond,

Oklahoma 73034, United States

Email:swoods9@uco.edu.
} 